See Article page 338.

\section{Commentary: One plus one does not always equal two: Mitochondrial cardioprotection}

\author{
Alvise Guariento, MD, ${ }^{\mathrm{a}}$ Ilias Doulamis, $\mathrm{MD}, \mathrm{PhD},{ }^{\mathrm{b}}$ \\ and Vladimiro Vida, $\mathrm{MD}, \mathrm{PhD}^{\mathrm{a}}$
}

Several mitochondrial pathways have been targeted to find the Holy Grail for cardioprotection. In their recent paper, Ahmad and colleagues ${ }^{1}$ investigated the cardioprotective properties of diazoxide (DZX) and mitochondria-targeted s-nitrosating agent separately and in combination. Based on their in vitro and ex vivo studies, the authors concluded that these 2 substances provide cardioprotection when administered separately, but this effect is reduced when combined. This is an intriguing finding, as one would expect a synergistic effect instead of a potential mutually exclusive mechanism of action (Figure 1). This study provides some insight into the mechanisms of action of DZX, a drug that has been studied for its possible cardioprotective effects in preclinical models. ${ }^{2}$

However, while intriguing, their hypotheses would benefit from being approached from a categorical and empirical perspective. First, the use of an in vivo model would add to the translational clinical significance of these results. In the present study, their functional data are derived from a 90-minute ex vivo cardiac reperfusion period. Previous reports have shown that 120 minutes of reperfusion provide the best reliable assessment of infarct size in hearts perfused on a Langendorff apparatus. ${ }^{3}$ Another point to consider is the fact that mitochondrial function was not evaluated at the end of the experiment.

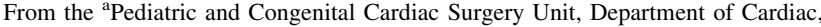
Thoracic and Vascular Sciences, University of Padua, Padua, Italy; and ${ }^{\mathrm{b}}$ Department of Surgery, Johns Hopkins University School of Medicine, Baltimore, Md. Disclosures: The authors reported no conflicts of interest.

The Journal policy requires editors and reviewers to disclose conflicts of interest and to decline handling or reviewing manuscripts for which they may have a conflict of interest. The editors and reviewers of this article have no conflicts of interest.

Received for publication Aug 12, 2021; revisions received Aug 12, 2021; accepted for publication Aug 12, 2021; available ahead of print Aug 30, 2021.

Address for reprints: Alvise Guariento, MD, Pediatric and Congenital Cardiac Surgery Unit, Department of Cardiac, Thoracic, Vascular Sciences and Public Health, University of Padua, Via Giustiniani 2, 35100 Padua, Italy (E-mail: alvise. guariento@hotmail.com).

JTCVS Open 2021:8:357-8

2666-2736

Copyright (C) 2021 The Author(s). Published by Elsevier Inc. on behalf of The American Association for Thoracic Surgery. This is an open access article under the CC BY-NC-ND license (http://creativecommons.org/licenses/by-nc-nd/4.0/)

https://doi.org/10.1016/j.xjon.2021.08.016
}

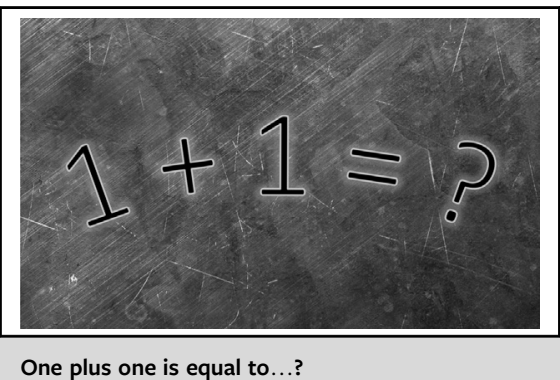

One plus one is equal to...?

CENTRAL MESSAGE

Mitochondrial cardioprotection pathways are difficult to predict and may not always lead to the expected result.

Mitochondrial isolation and ATP content would further confirm their findings. In addition to these limitations, physiological differences between murine models and humans should be considered. In fact, mice have been shown to exhibit increased levels of xanthine oxidase (which is absent in humans or other animal models such as rabbits), an enzyme that is directly involved in the formation of reactive oxygen species and may be implicated in the cardioprotective effect of DZX and mitochondriatargeted s-nitrosating agent. ${ }^{4}$ Finally, the authors state that they used both male and female mice. As acknowledged by them, it would be interesting to evaluate any sex-specific observations, given that mitochondrial oxygen consumption and $\mathrm{Ca}^{2+}$ are modulated by sex and play a significant role in the sex-based response to ischemiareperfusion. ${ }^{5}$

Nevertheless, this interesting study adds another path down the road that will ultimately lead to understanding

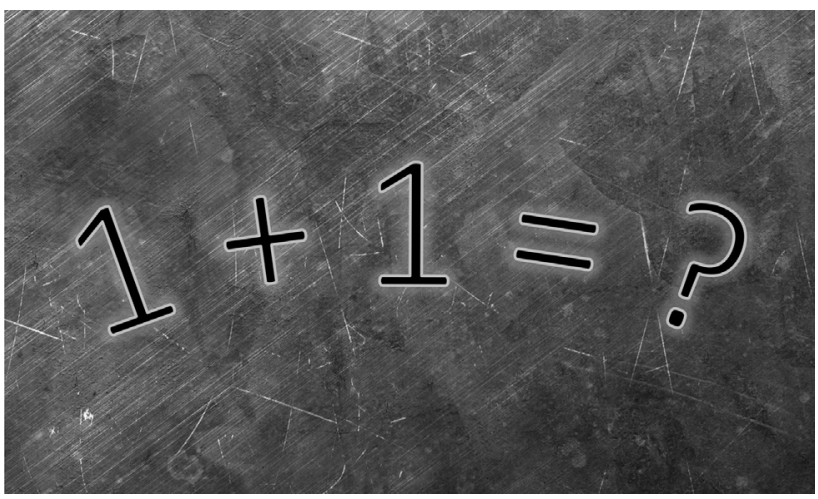

FIGURE 1. One plus one is equal to...? 
the whole picture of mitochondria and cardioprotection. The authors should be commended for their work, and future follow-up studies on these preliminary observations are keenly awaited.

\section{References}

1. Ahmad T, Wang J, Velez AK, Suarez-Pierre A, Clement KC, Dong J, et al. Cardioprotective mechanisms of mitochondria-targeted S-nitrosating agent and adenosine triphosphate-sensitive potassium channel opener are mutually exclusive. $J$ Thorac Cardiovasc Surg Open. 2021;8:338-54.
2. Hsieh YJ, Wakiyama H, Levitsky S, McCully JD. Cardioplegia and diazoxide modulate STAT3 activation and DNA binding. Ann Thorac Surg. 2007; $84: 1272-8$.

3. Doulamis IP, Guariento A, Duignan T, Orfany A, Kido T, Zurakowski D, et al. Mitochondrial transplantation for myocardial protection in diabetic hearts. Eur J Cardiothorac Surg. 2020;57:836-45.

4. De Jong JW, Van der Meer P, Nieukoop AS, Huizer T, Stroeve RJ, Bos E. Xanthine oxidoreductase activity in perfused hearts of various species, including humans. Circ Res. 1990;67:770-3.

5. McCully JD, Rousou AJ, Parker RA, Levitsky S. Age- and gender-related differences in mitochondrial oxygen consumption and calcium with cardioplegia and diazoxide. Ann Thorac Surg. 2007;83:1102-9. 